\title{
Vivienda social y pertenencia socioterritorial: el caso de la colonia González Gallo en Guadalajara, México
}

Fernando Cornejo. Escuela Superior de Arquitectura, Guadalajara, México.

RESUMEN | Tomando como punto de partida los recuerdos personales y las memorias compartidas en torno a las prácticas cotidianas de los primeros habitantes de la colonia González Gallo -construida hace cerca de setenta años en Guadalajara, México-, esta investigación aborda la importancia que tuvieron tanto el proyecto urbano-arquitectónico como el perfil social de las familias en la generación de un fuerte sentido de pertenencia socioterritorial. Andadores peatonales, espacios públicos centrales y bienes y servicios cercanos se convirtieron en lugares de encuentro e interacción para grupos familiares que, si bien tenían niveles socioeconómicos distintos, compartían el hecho de contar con hijos pequeńos así como ser propietarios por primera vez en sus vidas de la casa que habitaban, lo que facilitó la construcción de fuertes lazos vecinales que en algunos casos se mantienen hasta hoy en día.

PALABRAS CLAVE | integración social, morfología urbana, satisfacción residencial.

ABSTRACT | Considering the personal and shared memories of daily practices of the first inhabitants of the González Gallo neighborhood - built almost 70 years ago in Guadalajara, Mexico - this research addresses the importance of both the urban architectural project and the profile of the families in generating a strong sense of socio-territorial belonging. Pedestrian walkways, central public spaces, and nearby goods and services became places of encounter and interaction for family groups. Although they had different socioeconomic levels, they shared the fact of having small children and being first-time homeowners, which facilitated the construction of strong neighborhood bonds, that in some cases, are maintained to the date.

KEYWORDs | social integration, urban morphology, residential satisfaction.

Recibido el 7 de noviembre de 2019, aprobado el 30 de marzo de 2020.

E-mail: fcornejo@esarq.edu.mx 


\section{Introducción}

Las pertenencias socioterritoriales se conforman a partir de dos elementos, separados en términos analíticos, pero que operan de forma conjunta en la realidad: los grupos sociales a los que los sujetos se encuentran vinculados -ya sea por lazos de sangre, origen cultural, afiliación institucional, elección personal o localización residencial, por ejemplo-, y el territorio, entendido, desde una dimensión cultural, como espacio apropiado y valorado funcional y/o simbólicamente por los sujetos a través de sus prácticas y representaciones (Giménez, 2007; Haesbaert, 2011; Raffestin, 2013). En ese sentido, su estudio nos permite conocer, entre otras cosas, el grado de integración social y la vinculación que existe en y con el territorio, las razones y elementos que posibilitan dicha integración y vinculación, así como los niveles de satisfacción que genera en los sujetos y el impacto que produce en sus modos de vida.

La investigación que aquí se presenta aborda, como caso de estudio, el de la colonia de la Habitación Popular N. ${ }^{\circ}$ 1, o González Gallo -como se la nombró a los pocos años de inaugurada-, localizada en la ciudad de Guadalajara, Jalisco, México. Este interés se debe a que los antiguos pobladores de la colonia construyeron un fuerte sentido de pertenencia socioterritorial que en muchos casos se mantiene hasta hoy en día, casi setenta ańos después de su fundación, incluso a pesar de que muchos de sus primeros pobladores -los que aún viven- ya no habitan ahí. En buena medida, dicha pertenencia es resultado del proyecto urbano-arquitectónico, el perfil social de sus residentes, las expectativas de vida que se les abrió a las familias con la posesión de una casa propia, así como del contexto sociohistórico de la Guadalajara de mediados del siglo xx.

El objetivo de esta investigación es conocer cómo las características socioespaciales de la colonia González Gallo posibilitaron que sus primeros habitantes construyeran un fuerte sentido de pertenencia socioterritorial. En específico, se busca comprender la relación que se establece entre espacio construido y colectivos sociales a través del estudio de las prácticas y las representaciones de los sujetos, que es finalmente donde se articula y adquiere sentido dicha relación, misma que no es determinante ni unidireccional, sino dinámica y variable.

Algunas preguntas que guían este trabajo son las siguientes: ¿Cómo afectó la configuración de los espacios al interior de la colonia las prácticas que realizaban los sujetos en ella? ¿Qué papel desempeñaron los bienes y servicios que se ofertaban en ese espacio en el tipo de relaciones que establecieron los sujetos? ¿Qué características de los habitantes contribuyeron al establecimiento de relaciones sociales entre los vecinos? Se pretende generar una reflexión sobre cómo ciertos elementos urbano-arquitectónicos -como calles peatonales y espacios públicos centrales-, la existencia de bienes y servicios cercanos y accesibles a la población -escuelas, hospitales, mercados y rutas de transporte público-, y la vinculación entre los habitantes -a través de relaciones vecinales, de amistad o de otro tipo, como las relativas a sus creencias religiosas-, coadyuvan a la integración social de los sujetos.

Un segundo objetivo que persigue este trabajo, más discreto en su abordaje, pero no por ello menos importante, es aportar elementos que ayuden a repensar 
cómo, dónde y con qué características se construye vivienda actualmente, sobre todo ante el gran fracaso que ha supuesto la construcción de viviendas de carácter popular en las periferias de las ciudades, alejadas y en ocasiones desconectadas del núcleo urbano, sin ninguna clase de bienes y servicios cercanos y accesibles para la población, lo que se traduce en falta de arraigo y pertenencia (Siqueiros, 2012). Además de estas urbanizaciones periféricas, realizadas con la anuencia del Estado, en el caso de Guadalajara los fraccionamientos cerrados -o cotos, como se les conoce localmente- desde que comenzaran a popularizarse por allá en los años sesenta han supuesto un nuevo tipo de ruptura del tejido urbano y, por tanto, del tejido social, y un desprecio por lo público como bien común.

Esta investigación se llevó a cabo entre febrero de 2018 y julio de 2019, y consistió en la realización de siete entrevistas de corte cualitativo a un total de diez personas, de las cuales cuatro fueron mujeres y seis hombres, cuyas edades oscilan entre los 65 y los 80 años de edad. La mayoría de ellas se encuentra jubilada de profesiones tan variadas como el ejercicio de la contaduría, el magisterio, la arquitectura, la ingeniería o la medicina, mientras que otras tres se encontraban laboralmente activas, dos de ellas como secretarias y una más atendiendo una papelería. Para contactar a los sujetos, se utilizaron dos vías. En primer lugar, a través de colegas y conocidos, quienes me presentaron a personas cuya característica principal era que habían vivido en la colonia durante los primeros ańos de su construcción, pero que luego se habían mudado con sus familias a otro lugar. Posteriormente, por medio de la técnica de la bola de nieve, se contactó con sujetos que siguen viviendo en la colonia, ya sea porque nunca se mudaron, o porque regresaron después de haber vivido algún tiempo en otro sitio.

Asimismo, se revisaron publicaciones periódicas de la época, específicamente del periódico El Informador (el más antiguo y con mayor tiraje de la ciudad), considerando un periodo que va de septiembre de 1947 a mayo de 1954, donde se recoge información sobre la creación del Patronato de la Habitación Popular y la construcción de las distintas etapas de la colonia. Se consultaron también publicaciones académicas que abordan el tema tanto de la vivienda como del contexto histórico de la ciudad de Guadalajara. Sin embargo, no fue posible acceder a documentación generada de primera mano por el Patronato respecto al proyecto de la Habitación Popular, ya sea porque se encuentra extraviada en algún archivo municipal o porque ya no existe.

En términos temporales, la información que aquí se presenta, relativa a la experiencia de los sujetos entrevistados, abarca un periodo aproximado de veinticinco años a partir de la fundación de la colonia, cuando se vivió una época que podríamos catalogar como dorada en las relaciones que sostuvieron los vecinos. Posteriormente, la colonia entró en un periodo de decadencia, desencadenado por la rotación de vecinos, la urbanización de las zonas colindantes, el aumento en los niveles de inseguridad, así como por las nuevas dinámicas en las que entraron sus habitantes debido al proceso natural de maduración y envejecimiento de la población.

El presente artículo se encuentra estructurado de la siguiente forma. En primer lugar, se desarrolla una discusión teórica sobre la construcción de pertenencias socioterritoriales y el proceso de habitar. En segundo lugar, se aborda el papel del 
Patronato de la Habitación Popular en la construcción de la colonia, las características urbano-arquitectónicas que esta tuvo en sus inicios, así como el perfil de la población que llegó a habitarla. Posteriormente se presentan los resultados del trabajo de investigación, centrados en las prácticas de apropiación del espacio y estructurados a partir de la edad de los sujetos.

\section{Pertenencias socioterritoriales y el proceso de habitar}

La vida de los sujetos transcurre en una diversidad de espacios, los cuales pueden ser tan variados como sean los roles que las personas cumplen en la sociedad. Al ser donde se materializa su existencia a partir de las prácticas que realizan y de las relaciones que establecen con otros sujetos, dichos espacios desempeńan, de manera diferenciada, un papel clave en la conformación de las identidades y, por tanto, de las pertenencias socioterritoriales. Lejos de ser excepcionales en la experiencia del sujeto, las pertenencias socioterritoriales responden a una serie de necesidades básicas, ya que "las personas necesitan identificarse con un grupo o un territorio específico, a la vez que necesitan sentirse parte de un colectivo y sentirse arraigados en un lugar concreto" (Ortiz-Guitart, 2006, p. 69).

La pertenencia socioterritorial se conforma a partir de dos elementos. Por un lado, de un colectivo o grupo social, con el cual se tiene o se establece algún tipo de relación significativa al compartir con sus integrantes un mínimo de valores, principios, códigos, experiencias, expectativas, prácticas, estilos de vida, entre otras cosas, lo que permite la construcción de un nosotros. Por otro lado, de un territorio, espacio apropiado y convertido en lugar a partir de las prácticas y representaciones de los sujetos. Esta relación y vinculación entre colectivo social y territorio, a través de la cual los sujetos adquieren y comparten "el complejo simbólico-cultural" del lugar donde se está (Giménez, 2007), es en buena medida resultado del proceso de habitar.

Para Heidegger (1994), el concepto 'habitar' deriva, por lo menos en el alto alemán antiguo, de la palabra Bauen, asociada con los términos 'construir' y 'cuidar', pero también con el verbo bin, que significa 'ser'. En ese sentido, para este autor, el hombre es en la medida en que habita en la tierra, donde cuida y construye. El habitar, por tanto, puede considerarse como una experiencia primigenia que tiene el ser humano en el espacio, lo cual solo es posible a través de las prácticas (Lindón, 2014). El sujeto es en la medida en que habita, y habita en la medida en que actúa sobre una realidad que reconoce y en la que se reconoce; una realidad en la que es capaz de ubicarse y establecer, a través de sus prácticas y representaciones, un orden espacio-temporal determinado (Duhuau \& Giglia, 2008; Giglia, 2012).

La vida cotidiana constituye el principal orden espacio-temporal en el que se encuentran insertos los sujetos, por lo que se le conoce como "suprema realidad" (Berger \& Luckmann, 2005). Este orden se ve reflejado en las prácticas ordinarias que realizan los sujetos -como trabajar, consumir o realizar actividades de ocioen espacios y tiempos determinados, lo que le brinda a la vida cotidiana cierta regularidad y estructura (Berger \& Luckmann, 2005; Juan, 2008; Lindón, 2000; Reguillo, 2000). Puede decirse que en esta diversidad de actividades el hombre "se 
objetiva", y "el hombre, formando su mundo (su ambiente inmediato) se forma también a sí mismo" (Heller, 1977, p. 24).

Este orden, construido y mantenido en el día a día, es indisociable del espacio en el cual se objetiva. Esto lleva a Duhau y Giglia $(2008,2016)$ a plantear la existencia de un orden urbano, conformado por una serie de normas y reglas, tanto formales como informales, en las que los sujetos se apoyan al momento de realizar sus prácticas, incidiendo en la forma en que usan y se apropian de los espacios públicos. Dicho orden, por otro lado, es siempre histórico y se encuentra moldeado por la cultura, por lo que es posible hablar, de acuerdo con Giglia (2012), de "culturas del habitar", asociadas a diferentes tipos de hábitat y a la forma de habitarlos. Sin embargo, no es posible hablar de determinismos ecológicos (asociados a la configuración de los espacios) o culturales (asociados a los grupos que habitan esos espacios), sino de influencias que afectan de manera diferenciada los sistemas de comportamientos (Castells, 1976).

La forma como se incorporan y reproducen estos órdenes que regulan la vida social es indisociable de aquellas disposiciones prácticas y esquemas de percepción, valoración y clasificación que adquieren los sujetos al interior de sus grupos de pertenencia. Estos habitus, como los denomina Bourdieu (2007, 2009, 2011), son producto de los condicionamientos de clase, asociados con la posición -siempre relacional y distintiva- que ocupan los sujetos dentro de un espacio social. Los habitus condicionan, a su vez, la forma como los sujetos leen, interpretan y reproducen un orden social determinado, el cual se encuentra objetivado en el espacio físico, por lo que esta noción nos permite "entender que el espacio lo ordenamos, pero también que el espacio nos ordena, es decir, nos pone en nuestro lugar, enseñándonos los gestos apropiados para estar en él, e indicándonos nuestra posición con respecto a los demás" (Giglia, 2012, p. 16).

La vinculación entre espacio y colectivos sociales, condición necesaria para la generación de un sentido de pertenencia socioterritorial, puede asociarse con el espacio de representación (o espacio vivido), de Lefebvre. Para este autor, este tipo de espacio "se vive, se habla; tiene un núcleo o centro afectivo (...). Contiene los lugares de la pasión y de la acción, los de las situaciones vividas" a través del tiempo (2013, p. 100). Esta noción forma parte de una tríada conceptual, de la que hacen parte las prácticas del espacio (lo percibido) y las representaciones del espacio (lo concebido). La práctica espacial está asociada a los modos de producción dominantes en un momento histórico determinado (como el capitalismo), ya que estos reconfiguran la forma urbana y regulan el tiempo de las prácticas. Las representaciones del espacio, por su parte, se asocian con un saber, mezcla de conocimiento e ideología, a partir de lo cual se proyecta y construye una cierta morfología de la ciudad.

En cuanto al tejido urbano de las ciudades, o su ecosistema, este interesa no solo por su morfología (espacio concebido), sino por la vida social y cultural que ahí se genera (espacio vivido) (Lefebvre, 1978, 2013), entendiéndose que tanto el espacio construido como los grupos sociales que lo utilizan se influyen y moldean mutuamente, afectando las formas como los sujetos habitan y se apropian de los lugares. Esto es particularmente cierto al vivir los sujetos mucho tiempo en un lugar, ya que lo transforman a su propia imagen -0 , dicho de otra forma, le imprimen 
una identidad determinada asociada con el grupo-, al mismo tiempo que son transformados por el lugar (Halbwachs, 2004). Pero, ¿cuáles son esos lugares que habitan los sujetos en el marco de su vida cotidiana, donde construyen un sentido de pertenencia socioterritorial? Son varios, pero centro mi atención en los más básicos, asociados con el lugar de residencia.

En la experiencia de vida de los sujetos, la casa es, por lo general, el principal punto de referencia que tienen para ubicarse en el espacio -que no solo es físico, sino también social- y relacionarse con el mundo que los rodea. En ese sentido, "la casa constituye el primero y más íntimo objeto de identidad, es la manera primaria de construir la pertenencia a un lugar" (Esquivel-Hernández, 2005, p. 80). Sin embargo, la pertenencia socioterritorial no hace referencia -por lo menos en este trabajo- a este tipo de espacios, asociados en este caso a un grupo primario como lo es la familia nuclear. Más bien el concepto hace referencia a aquellos espacios por fuera del ámbito doméstico donde se entra en contacto con la otredad, y donde se construyen, a través del tiempo, distintos tipos de relaciones sociales, se establece cierto grado de familiaridad y se genera entre los sujetos un sentimiento de destino compartido. Un nosotros.

La casa, como lugar de residencia, se localiza en un contexto socioespacial más amplio, como pueden ser los barrios, colonias o fraccionamientos, por mencionar algunos. En el caso de Guadalajara, el término 'barrio' hace referencia tanto a una división socioterritorial como a un tipo de urbanismo particular que surge durante la época colonial y que se mantiene prácticamente hasta principios del siglo $\mathrm{xx}$. Los barrios en referencia se caracterizan por tener una serie de elementos centrales que organizan la vida social de los sujetos, siendo el templo el principal elemento de esta organización, seguido de los mercados como fuentes primarias de abastecimiento. Asimismo, suelen florecer en su interior distintos tipos de negocios familiares que satisfacen buena parte de las necesidades de sus residentes, por lo que funcionan, en cierta forma, como microuniversos urbanos.

Por su parte, las colonias y fraccionamientos se caracterizan principalmente por el predominio de la función residencial, y si bien pueden tener en su interior templos o mercados, estos no son elementos centrales -aunque pueden llegar a serlo- en la organización socioespacial, como sí lo son en los barrios. Y en cuanto al tipo y cantidad de comercios que pudieran contener en su interior, estos dependerán del nivel socioeconómico y de las necesidades que tengan sus residentes, siendo por lo general escasos o nulos en los grupos de mayor poder adquisitivo, y múltiples y variados en los sectores populares, ya que muchas viviendas son adaptadas no solo para vivir en ellas, sino también para trabajar, convirtiéndose en una fuente de ingresos para las familias.

En el caso particular de los barrios y colonias populares, estos son vividos y experimentados por los sujetos de forma diversa. Por un lado, son lugares donde pueden llevar a cabo distintas actividades cotidianas a partir de las cuales generan relaciones vecinales, sean estas activas o pasivas. Son también, por otro lado, espacios de transición entre el espacio privado de la casa y el espacio público de la ciudad, por lo que el barrio puede considerarse como un espacio público privatizado (Mayol, 2006). Asimismo, son espacios donde los sujetos entran en contacto con la otredad, 
a partir de lo cual adquieren, modifican y ponen en práctica una serie de valores, actitudes, predisposiciones -en otras palabras, un habitus socioespacial-, al tiempo que incorporan y construyen un orden producto del proceso de habitar.

Ahora bien, cuando se estudian aquellas pertenencias socioterritoriales que forman parte del pasado biográfico de los sujetos y de la historia de sus grupos, la memoria, como fuente de información, se convierte en un recurso fundamental. La memoria permite reconstruir, a la luz del presente y a través del discurso, aquello que pasó o se cree que pasó, otorgándole nuevos contenidos y significados. Selectiva y subjetiva a un tiempo, la memoria se compone de recuerdos y de olvidos (González-Varas, 2014), vinculados en ocasiones con la morfología de los espacios (Nates, 2011). Al explorar en la memoria de los sujetos, es posible acceder a las experiencias que estos tuvieron en torno al proceso de habitar y conocer, a partir de ello, el grado de apropiación territorial y de integración social que lograron en un momento determinado.

\section{El proyecto de la Habitación Popular N.o 1 en la Guadalajara de mediados del siglo $\mathrm{xx}$}

La década de los años cuarenta marca el inicio de un crecimiento acelerado tanto de la población como de la mancha urbana en la ciudad de Guadalajara debido a una diversidad de factores, entre los que destacan la migración hacia la ciudad desde otros núcleos poblacionales más pequeños, la política de sustitución de importaciones como consecuencia de la Segunda Guerra Mundial, el surgimiento y consolidación de la pequeña y mediana industria, la aparición comercial de una serie de servicios, la popularización del uso del automóvil, así como una particular idea de modernización respecto a la traza urbana -reflejada en la ampliación de calles y la construcción de avenidas, lo que supuso la destrucción de fincas históricas principalmente en el centro de la ciudad-, todo lo cual transformó para siempre la ciudad de Guadalajara y sus municipios periféricos.

A partir de ello, la ciudad pasó de tener 229.226 habitantes asentados en 2.620 hectáreas en 1940, a 330.226 habitantes en 4.180 hectáreas en 1950, mientras que para 1960 estas últimas cifras prácticamente se habían duplicado, alcanzando los 736.800 habitantes localizados en una extensión de 9.047 hectáreas (NúñezMiranda, 1999). Así, tanto las migraciones como el crecimiento natural de la población generaron una fuerte demanda de vivienda, por lo que "los ańos 1940-1970, representan un periodo de fuerte expansión en la urbanización de la ciudad, y en la consolidación de una política de accesión a la propiedad privada" (López-Moreno, 1996, p. 304). Sin embargo, muchas viviendas siguieron presentando carencias respecto a la prestación de servicios básicos, además de que los espacios no siempre eran suficientes para el número de residentes.

Ante esta necesidad de vivienda que experimentaban los pobladores de la ciudad, en 1947 se decretó, bajo el mandato del gobernador Jesús González Gallo -quien gobernó el estado de Jalisco de 1947 a 1953-, la Ley de Fomento de la Habitación Popular. A partir de esta ley se creó el Patronato de la Habitación Popular, que funcionó desde esa fecha hasta el año de 1986, construyendo un total de nueve 
CEURE | VOL 48 | $\mathrm{N}^{\mathrm{O}}$ I43 | ENERO 2022 | pp. I-20

colonias y 2.145 habitaciones en la ciudad de Guadalajara (Vázquez, 1992). Sin embargo, no logró cumplir el propósito para el cual fue creado -por otra parte, imposible de cumplir-, que era el de solucionar el problema de la habitación popular ("El proyecto...", 9 de septiembre de 1947).

La Ley para el Fomento de la Habitación Popular contemplaba, en su artículo 16, la posibilidad de que el Estado, a petición del Patronato, expropiara terrenos para la construcción de vivienda. De forma expresa, se pedía priorizar la adquisición de vecindades que no cumplieran con unas condiciones mínimas de higiene (“El proyecto...", 9 de septiembre de 1947). Esto suponía el reconocimiento de las precarias condiciones de vida que prevalecían particularmente en el centro de la ciudad, así como la necesidad del gobierno de reubicar a la población (Arias, 1992).

Conformado por los sectores público y privado, el Patronato de la Habitación Popular se caracterizó por ser autónomo, contar con personalidad jurídica propia y estar descentralizado del Estado ("El proyecto...", 9 de septiembre de 1947). Su función principal era construir casas para vender o para rentar, y aunque aparentemente otra de sus funciones era la de otorgar créditos para la construcción, reconstrucción o adquisición de vivienda, estas no se pusieron en práctica (López-Moreno, 1996). El financiamiento de los conjuntos habitacionales corría a cargo del sector público, mientras que la construcción recaía en el sector privado. El sector social, por su parte, solo era contemplado como usuario o beneficiario final de esas construcciones (López-Moreno, 1996).

En el primer informe de actividades del Patronato se menciona que dichas colonias tenían que estar en terrenos accesibles económicamente, colindantes con la zona urbanizada, no tan alejados del centro de la ciudad, y debían contar con vías de comunicación, así como con toda clase de servicios públicos, lo que les permitiría funcionar como "verdaderas células urbanas" y, a sus habitantes, "vivir cómodamente" (Vázquez, 1992, pp. 56-57). El objetivo del Patronato era, de acuerdo con el Lic. Palomera, "dar oportunidad a las personas de bajos recursos de acceder a una vivienda, con condiciones de crédito amplias y sin intereses" (López-Moreno, 1996, p. 351). Así, por ejemplo, para acceder a una vivienda era necesario pagar inicialmente $10 \%$ de su costo, y el resto en mensualidades sin intereses durante los siguientes diez ańos. Dichas casas pasaban a formar parte de un régimen de patrimonio familiar, por lo que no podían venderse si antes no se comprobaba que el beneficiario había adquirido una mejor. Estuvieron pensadas para ser adquiridas por cinco sectores de la población, agrupados de la siguiente forma: el organizado (representado por obreros sindicalizados), el libre (trabajadores no sindicalizados), el de los burócratas del Estado y del municipio, el de los maestros del Estado y particulares, y finalmente el de burócratas y maestros federales ("El Segundo...", 1 de enero de 1951). Además, y de acuerdo con los criterios de selección -muy apegados a una moral conservadora, propia de la región y de la época-, las personas que desearan adquirir una casa tenían que ser aquellas:

a) cuyo medio exclusivo o principal de sostenimiento fuese la retribución de su trabajo; b) que fueran cumplidos en sus compromisos familiares y patrimoniales; c) que estuvieran legítimamente unidos en matrimonio, o en unión legal pero con 
hijos; d) que no fueran jugadores o alcohólicos habituales; e) que no tuvieran bienes raíces. (López-Moreno, 1996, p. 352)

La colonia de la Habitación Popular N. ${ }^{\circ}$ (Figura 1) se construyó sobre un potrero llamado La Quinta, el cual fue adquirido en 1948 al suroriente de la ciudad, en los límites de la zona urbanizada de esa época (Ángel de León, 2001). El proyecto estuvo a cargo de los arquitectos Ignacio Díaz Morales y José Villagrán García, quienes buscaron generar una estructura urbana de carácter barrial que contara con todos los servicios (Rueda-Velázquez, 2019). En cuanto al diseńo de las casas, este fue sometido a concurso público y las construcciones resultantes se caracterizaron por ser de "estilo Tapatío" ("Convocatoria", 21 de enero de 1948; "El Patronato...", 3 de marzo de 1951). Esto se ve reflejado en el uso de tejas y vacíos triangulares, la construcción de patios centrales y traseros (los últimos pensados no solo como patios de servicio, sino también para tener animales de corral), y la existencia de unos cuartos ubicados en las partes frontales de las casas que podían ser adaptados como talleres para la realización de algún oficio, por ejemplo.

Figura I | Proyecto original de la colonia de la Habitación Popular N.o 1

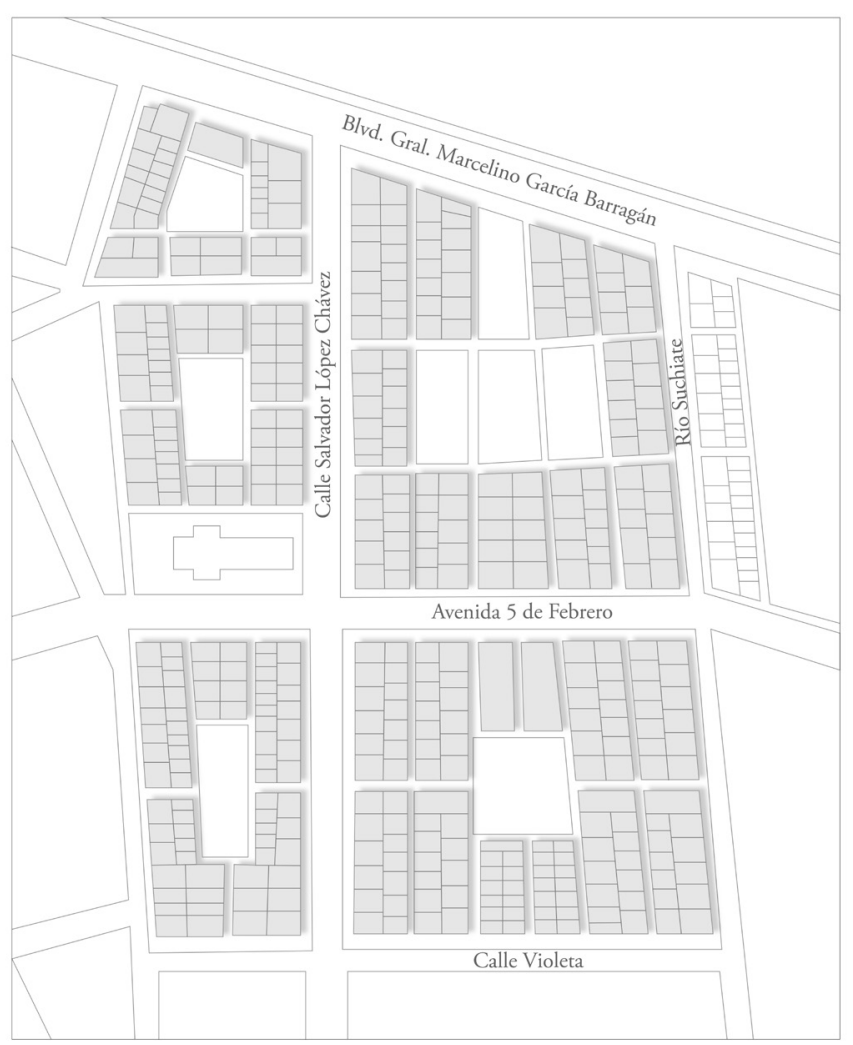

PROYECTO INICIAL

FUENTE: REDibujo DE NiCOLÁS LAURO A PARTIR DEL TRABAJO DE RUEDA-VELÁzQUEZ (2OI9) 
Figura 2 | Las cuatro etapas de la Habitación Popular N. ${ }^{\circ} 1$ y algunos lugares clave de la vida social

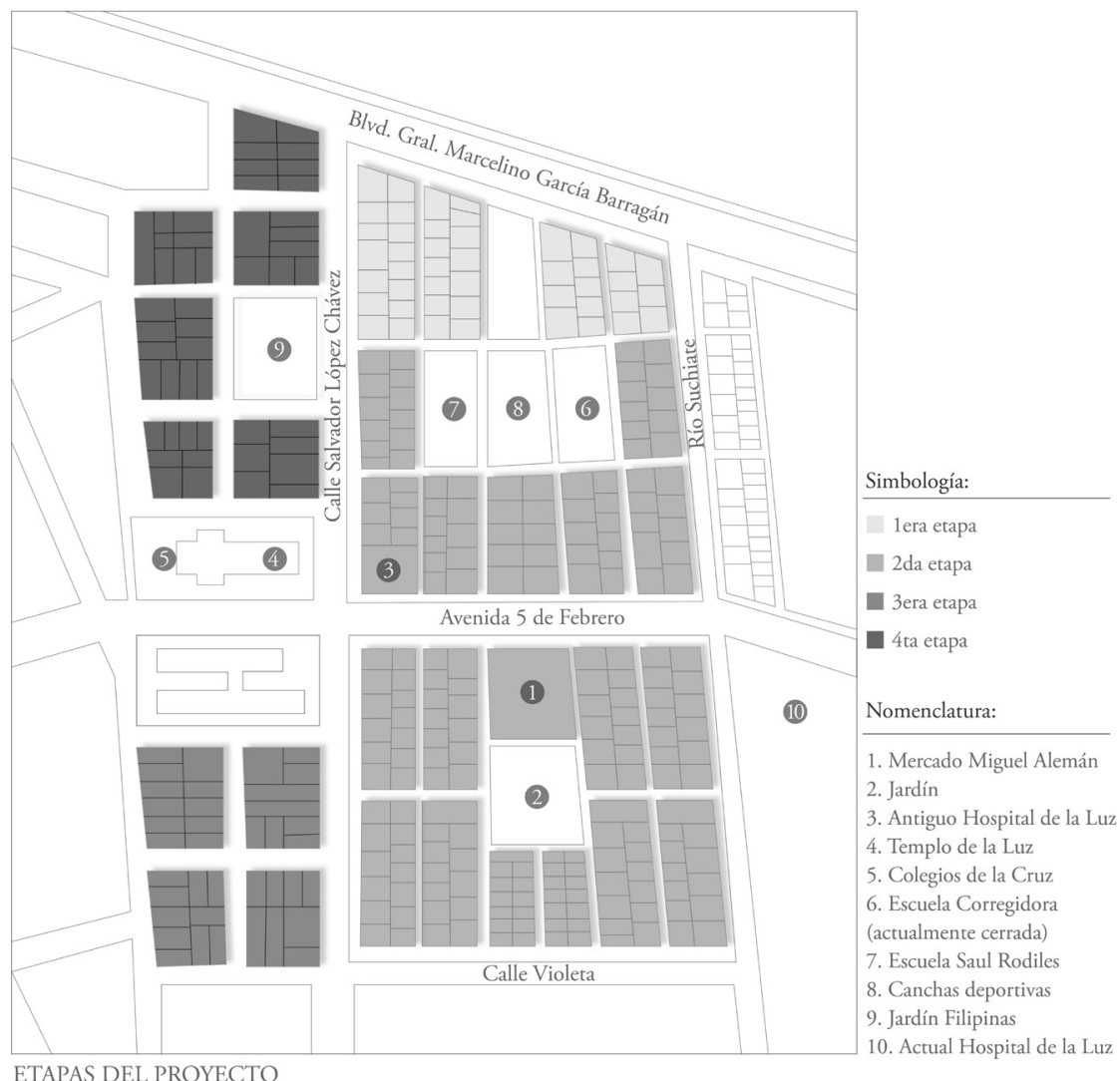

FUente: Redibujo de Nicolás lauro a PARTir del trabajo de ÁNGel de león (2OOI) Y RUEdaVELÁZQUEZ (2019)

La primera sección de la colonia constó de 200 viviendas, sorteadas los días 12 y 31 de diciembre de 1950 en el Teatro Degollado -ubicado en el corazón de la ciudad-, y los resultados se presentaron en los principales periódicos de la época. En total, fueron cuatro secciones las que se construyeron en un lapso aproximado de cinco años (Figura 2). En cuanto a las casas que se ofertaron, fueron de tres tamaños diferentes, contando las más chicas con sala-comedor, tres recámaras, baño, cocina, hall, patio y patio trasero. Las medianas, por su parte, incluían además una estanciacomedor y un pequeño taller doméstico, mientras que las más grandes contaban con los mismos espacios que las demás, solo que más amplios, y en algunos casos incluían cochera en lugar de taller (Ángel de León, 2001). La intención del Patronato era que las casas más pequeñas pudieran ser adquiridas por aquellos trabajadores que percibían un salario mínimo, y que reunieran "las condiciones de espacio, higiene y comodidad necesarios” (Vázquez, 1992, p. 57). 
Lo anterior no significa que el proyecto se redujera a una sola clase social, ya que la diferencia entre el tamaño de las casas y el precio de las mismas -que prácticamente era del doble entre las más baratas y las más caras- posibilitó que grupos con posiciones socioeconómicas diferentes compartieran un espacio en común, el de la colonia. Ahora bien, el hecho de que por primera vez en sus vidas estas familias fueran propietarias de las casas que habitaban (Figura 3), en una época en la que apenas un tercio de la población había alcanzado ese privilegio, es posible que haya influido de manera positiva en el comportamiento de los sujetos, particularmente en su disposición para establecer relaciones con sus vecinos.

\section{FIgURA 3 | Casas típicas}

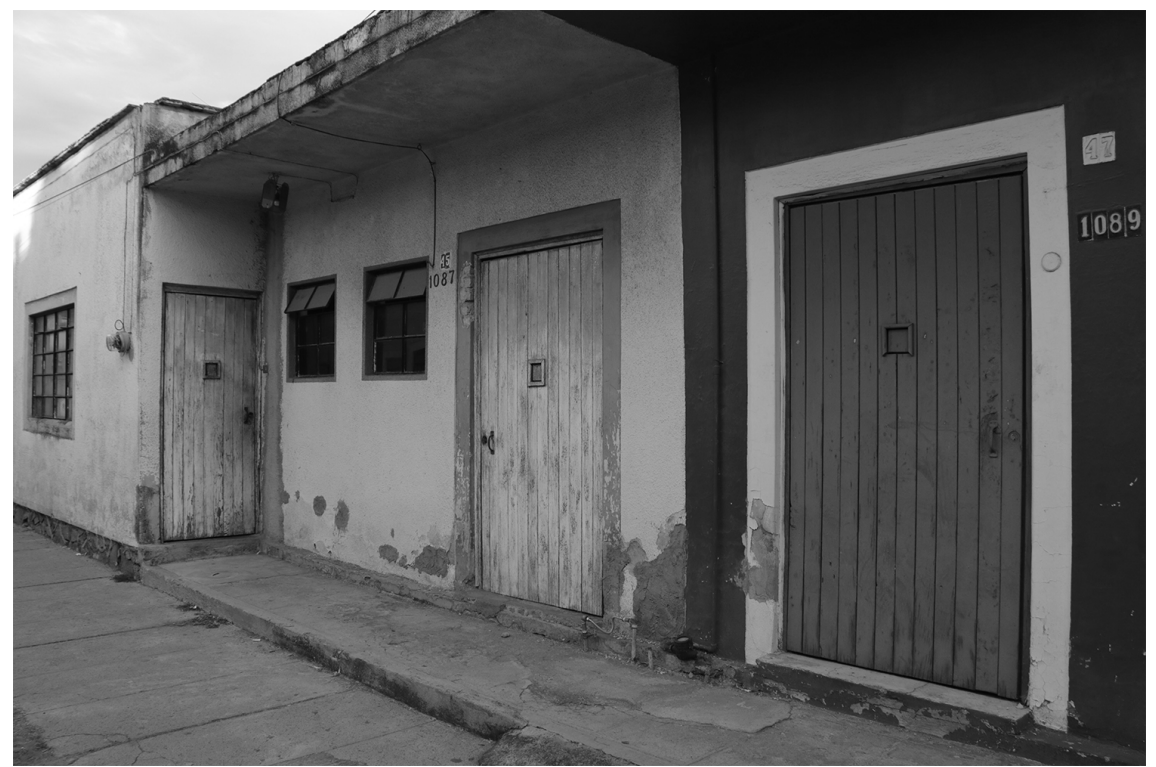

FUENTE: FOTOGRAFÍA DEL AUTOR (20I9)

En cuanto a las características de la colonia, esta contó desde un inicio con un mercado, un jardín con quiosco (Figura 4) -diseñado por los hermanos Luis y Juan José Barragán, el primero ganador del Premio Pritzker en el año de 1980-, dos escuelas primarias (una para niñas y otra para nińos), un terreno o llano entre las escuelas (donde más tarde se construyeron canchas deportivas), un templo católico dedicado a la Virgen de la Luz y, posteriormente, un hospital. Esto posibilitó que los vecinos pudieran satisfacer sus principales necesidades - de espacio público, educación, consumo, salud o de tipo religioso- sin tener que trasladarse hacia otros puntos de la ciudad. Asimismo, la mayor parte de las calles de la colonia eran andadores peatonales, por lo que no se permitía el paso de vehículos.

Por su ubicación, en los límites de la zona urbanizada, la colonia tuvo en sus primeros ańos un carácter insular, ya que buena parte de su perímetro se conformaba por terrenos baldíos o utilizados para la siembra. Sin embargo, nunca estuvo 
desconectada del resto de la ciudad, gracias a la existencia de vialidades y rutas de transporte público.

La colonia de la Habitación Popular fue inaugurada de manera oficial el 3 de marzo de 1951 por el entonces presidente Miguel Alemán Valdez. En septiembre de 1957, la colonia cambió de nombre, pasando de llamarse Habitación Popular N. ${ }^{\circ} 1$ a colonia Jesús González Gallo, como un homenaje al gobernador que la hizo posible.

FIGURA 4 | El jardín principal de la primera sección

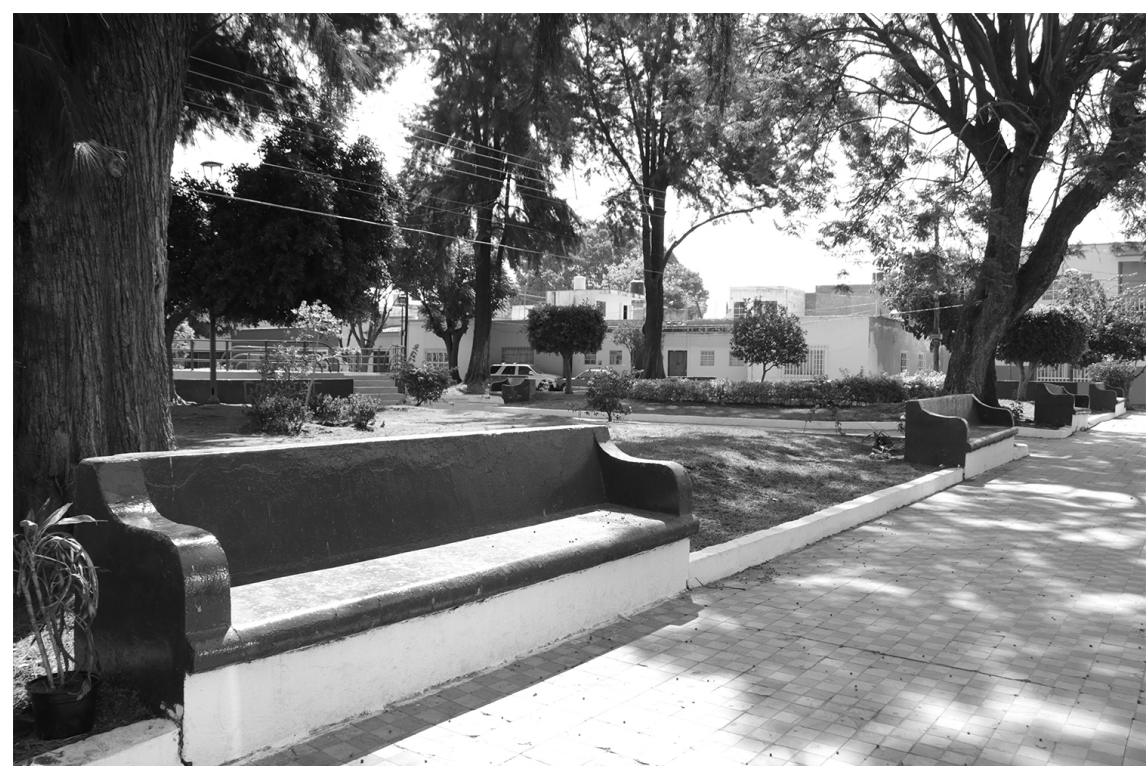

FUENTE: FOTOGRAFÍA DEL AUTOR (2020)

La apropiación del espacio: lugares, tiempos, prácticas y relaciones

Los sujetos se apropian del espacio y lo convierten en territorio a partir de sus prácticas y representaciones. Tanto las prácticas como las representaciones son posibles a partir de una serie de esquemas de percepción, valoración y acción. En otras palabras, de disposiciones prácticas; esto es, de un habitus que adquiere el sujeto al interior de sus grupos de pertenencia y en el marco de su vida cotidiana. En ese sentido, tienen un origen social y están ligados a un orden espacio-temporal. Los grupos de pertenencia, por un lado, inculcan una serie de valores y patrones de conducta que se encarnan en el sujeto y se objetivan en el espacio, mientras que la vida cotidiana ofrece, por otro lado, las coordenadas espacio-temporales que orientan y enmarcan la acción.

En cuanto a las prácticas cotidianas de los sujetos, se encuentran asociadas a la edad, el género y los roles que ellos cumplen en sociedad, entre otros factores. Los siguientes apartados se estructuran en torno a los diferentes grupos de edad, sin descuidar los demás factores antes mencionados. 


\section{El juego como medio de apropiación espacial en el caso de los nińos}

En el caso de los niños, estos tienen menos responsabilidades que cumplir en su vida diaria en relación con los adultos, siendo sus estudios -cuando ya están en edad de cursarlos- y la realización de algunas actividades domésticas sus principales ocupaciones formales, por llamarlas de alguna manera. Esto les permite contar con mucho tiempo libre, el cual emplean en actividades lúdicas -o informales-, mismas que resultan relevantes en su proceso formativo, pues a través de juegos aprenden a relacionarse con otros sujetos de su edad, desarrollan sus capacidades motoras, dan rienda suelta a su imaginación, al tiempo que despiertan y satisfacen su curiosidad respecto al mundo que los rodea.

Ahora bien, en el caso de la Habitación Popular N. ${ }^{\circ} 1$ o González Gallo, las calles peatonales con las que contó la colonia en un inicio les brindaron a los niños seguridad, al mismo tiempo que cierta libertad de acción.

...pues nos íbamos haciendo amigos y amigos y amigos, y al rato, como la calle

Río Papaloapan era peatonal, sin carros, sin vehículos, precisamente para darle a los habitantes libertad de caminar, a los nińos libertad de jugar... para andar para arriba y para abajo, y sin peligro, eso, sin peligro de un vehículo que los fuera a atropellar. (Ernesto, ${ }^{1}$ entrevista 2018)

Al ser esta colonia un espacio nuevo para niños y niñas, les ofreció la posibilidad de descubrirla y apropiársela al mismo tiempo que formaban relaciones de amistad con sus nuevos vecinos. Esta "aventura" -como la cataloga uno de los entrevistados-, entendida como una situación excepcional y emocionante que vivieron en su infancia, conecta de manera indisoluble dos dimensiones de la vida social: las prácticas de los sujetos, representadas principalmente a través del juego, las cuales les permitieron establecer y afianzar relaciones de amistad con sus coetáneos; y el espacio, convertido en territorio a partir de su apropiación física y simbólica.

Parte de las relaciones que entablaron los niños con esos otros que eran sus vecinos estuvieron mediadas y orientadas por personas adultas, particularmente por sus madres. Así, por ejemplo, el jardín y los andadores, al ser espacios públicos pensados para el uso y disfrute de los habitantes de la colonia, eran aprovechados por las madres para organizar comidas u otro tipo de actividades, lo que les permitía, tanto a ellas como a sus hijos, construir y reforzar sus vínculos de amistad, así como sentar las pautas de convivencia para esas relaciones que establecían con los vecinos.

Asimismo, al realizar las madres de familia algunas actividades en las puertas de sus hogares -como tejer, bordar o coser, por ejemplo-, les permitía, además de socializar con sus vecinas, cuidar de sus hijos que se encontraban jugando en la calle. Pero no solo las madres cuidaban de los niños, sino también los demás adultos que vivían o trabajaban en la colonia. En ese sentido, los infantes tenían una libertad con límites debido al orden social y a los valores imperantes en la colonia, mismos que los mayores hacían valer y respetar, sin que ello fuera origen de conflictos entre las familias o que detonara resistencias por parte de los menores. 
...yo me iba dos cuadras y si me veía la mamá de cualquier amigo "hey, ¿qué andas haciendo acá? Inmediatamente [truena los dedos]...” Nos devolvían, tenían autoridad; las maestras de la primaria y del kínder, tenían autoridad. Había mucho control. (Vicente, entrevista 2018)

El hecho de que los espacios de juego fueran las calles peatonales, el jardín y el llano, los cuales se encontraban cercanos y colindantes con las viviendas, permitía una mejor y más constante vigilancia de los nińos por parte de los adultos, quienes se hacían responsables de su crianza, generando de esta forma un fuerte sentido de comunidad y de destino compartido. En ese sentido, el proyecto de la habitación popular puede ser considerado un éxito, pues muestra que son las personas las que crían a los hijos, y no los espacios por sí solos, más allá de los diseños especiales y de los artefactos lúdicos con los que cuentan algunos de ellos, como es posible observar en un tipo de urbanismo de corte más funcionalista.

Los arquitectos urbanistas parecen no darse cuenta del alto porcentaje de adultos necesarios para criar a los niños en sus juegos informales. Tampoco parecen comprender que los espacios y las instalaciones no crían a los niños. Pueden ser complementos útiles, pero sólo las personas educan a los niños y los integran a una sociedad civilizada. (Jacobs, 2013, p. 111)

\section{Jóvenes, entre el control familiar y la búsqueda de espacios propios}

Por otro lado, en el caso de los adolescentes y de los jóvenes, estos empiezan a adquirir poco a poco más responsabilidades como parte de un entrenamiento social que los prepara para afrontar los retos de la vida adulta. En cuanto a las responsabilidades formales que tenían los jóvenes de la colonia en ese tiempo, eran el estudio y el trabajo en algunos casos las más importantes, mientras que sus actividades informales o de ocio, asociadas a su tiempo libre, estaban centradas sobre todo en socializar con los amigos, ya sea a partir de los deportes, la música, la bebida o las fiestas y reuniones.

$\mathrm{Al}$ parecer fueron pocos los adolescentes y jóvenes que llegaron a la colonia, ya que la mayoría de las familias lo hicieron con hijos pequeños. Sin embargo, los niños crecen. En las primeras décadas de vida de la colonia, parte de las prácticas de los adolescentes estuvieron en buena medida vigiladas y controladas por los padres. Así, algunas de las reuniones que se realizaban entre los adolescentes y jóvenes se hacían en casas particulares donde los padres estaban presentes, garantizando que existiera una "sana convivencia", sin la presencia de alcohol y cuidando que las reuniones no se prolongaran hasta muy tarde. En ese sentido, las prácticas se sometían tanto al orden espacial de la casa de los padres como a la regulación del tiempo en que tales actividades se realizaban.

En mi casa se preocupó mucho mi familia por unirlos y conservarnos en un ambiente sano. Se juntaban en mi casa y formaron fiestas de carnaval en donde iban todos disfrazados, y si iban a la casa de los Muñoz les daban permiso, porque ahí eran tardeadas y los papás siempre estaban al pendiente de los jóvenes (...) y pues era muy bonito porque eran fiestas y convivencias de tardeadas, nada de noche, no 
se les daba vino, se les daba algo de comer, y pues la convivencia... ¿sí??, era muy

valiosa. (Laura, entrevista 2019)

El género, entendido como una construcción social que define el papel que desempeñan hombres y mujeres en sociedad, determina en buena medida el tipo de actividades de ocio que pueden realizar los sujetos, así como los espacios donde estas se realizan. Mientras que las actividades de ocio de las mujeres jóvenes estaban más ligadas en la colonia a ambientes caseros -que también podríamos catalogar de "privados" o "íntimos"-, controlados por los padres, los varones tenían mayor libertad para estar en el espacio público de la calle, debido al control relativamente relajado que experimentaban por parte de sus familias -o, por lo menos, de algunas de ellasrespecto de sus actividades. Así, por ejemplo, en ciertas partes de la colonia, los jóvenes varones llegaron a organizar sus propias fiestas en la calle -lo que sin duda requería tanto del permiso de los padres como del consentimiento de los vecinos-, lo que les permitió fortalecer sus relaciones de amistad y construir, por fuera del ámbito doméstico pero dentro del espacio vecinal, una identidad propia a partir de sus deseos, intereses e inquietudes.

Otro tipo de prácticas que llevaban a cabo los hombres jóvenes, como reunirse en los espacios públicos o afuera de locales comerciales para charlar, beber y cantar, por ejemplo, no representaban ninguna amenaza a los códigos de convivencia más elementales que habían establecido los vecinos. Saludar a las personas, ser respetuosos con ellas e incluso ofrecerse para ayudarlas en caso de algún problema o necesidad son gestos en apariencia sencillos, pero significativos, que respetaban los jóvenes, lo que da cuenta de la interiorización de normas de comportamiento en el marco de un orden social determinado; es, además, una forma de reconocimiento de ese otro cercano que es el vecino, aquel con el que se comparte un espaciotiempo de cercanía.

Asimismo, fue relativamente común que algunos jóvenes se juntaran en grupos barriales o pandillas juveniles para defenderse o atacar a otros grupos similares pertenecientes a otras colonias. Algunas de las razones que se encontraban tras estos grupos están asociadas con el control que pretendían ejercer sobre las mujeres de la colonia, pues intentaban evitar que estas salieran de la misma o fueran visitadas por sujetos de otros lugares, como si fueran de su propiedad, un recurso destinado solo a aquellos que vivieran en la zona. Estos conflictos les permitían a los jóvenes reforzar sus lazos de amistad, por lo que la "integración social” que surgía con este tipo de conflictos es calificada como "ma-ra-vi-llo-sa" por uno de los entrevistados.

\section{Entre la formalidad y la informalidad en las relaciones entre adultos}

En el caso de los adultos, los roles que estos cumplen generalmente se caracterizan por un alto nivel de responsabilidad, como, por ejemplo, ser padres de familia -lo que implica educar a los hijos a partir de una serie de principios y valores, así como velar por su integridad y desarrollo-, o trabajar para conseguir el sustento de quienes conforman ese núcleo social de carácter primario. Este tipo de responsabilidades los sitúan en determinados espacios de la geografía urbana. En el caso de la colonia, quienes trabajaban, por ejemplo, lo hacían fuera de casa, en oficinas 
de gobierno, salones de clase o locales comerciales, por mencionar algunas de las principales ocupaciones. Quienes no trabajaban fuera de casa, particularmente las mujeres, cumplían con el rol de amas de casa -que es una forma de nombrar el trabajo doméstico-, lo que implicaba mantener un orden dentro de la vivienda, así como llevar la batuta en la crianza de los hijos.

Este tipo de actividades formales se acompañaban en el marco de la vida cotidiana en la colonia con otras más informales, como aquellas asociadas al rol de los residentes en tanto vecinos y amigos de los vecinos, que son las que aquí interesan. Un principio elemental para la convivencia entre los sujetos es compartir un mínimo de códigos en común, a partir de lo cual puedan comunicarse y establecer un orden particular de relación. Cosas en apariencia tan sencillas como el saludo amable, los buenos días y las buenas tardes, suponen algo más que aquello que se enuncia de manera literal. Supone, antes que todo, el reconocimiento de ese otro cercano que es el vecino, con el que se tiene un vínculo de carácter socioterritorial. Pero, además, estas relaciones pueden estrecharse y profundizarse, sobre todo si se comparten valores, actitudes y prácticas entre los grupos familiares, lo que lleva a desarrollar una mayor confianza entre los sujetos, así como un sentido de pertenencia socioterritorial más fuerte.

Ahora bien, dentro de las relaciones que establecieron los vecinos de la colonia González Gallo, y en las cuales es posible ver el grado de confianza que existía entre las familias, están no solo aquellas que dan cuenta del contacto recurrente para saludarse y saber cómo están los vecinos -que, más allá de lo protocolario que esto tiene, deja ver la preocupación y el interés que existía por el otro-, sino también aquellas a las que se recurre para satisfacer necesidades cotidianas muy elementales, como la falta de un producto de cocina.

Por otro lado, los espacios públicos y semipúblicos servían para el encuentro cotidiano de los vecinos. En el caso de los hombres, salían de sus casas después de regresar de sus trabajos para charlar y ponerse al día con sus pares, utilizando para ello principalmente los andadores peatonales. Por su parte, en el caso de las mujeres, quienes pasaban más tiempo en la colonia, se encontraban de manera frecuente en distintos puntos, como el mercado, las escuelas o las calles. Sin embargo, muchas de ellas también hacían uso del espacio en común que existía entre cada dos viviendas -una especie de banqueta de poco más de un metro de ancho a la que daban las puertas de las casas-, el cual era prácticamente la antesala de la calle. Que las mujeres utilizaran estos espacios para realizar distintos tipos de actividades -como bordar, cuidar a los nińos o simplemente charlar- reivindicaba un derecho, que es el de la casa propia, y marcaba también una zona de transición y traslape de valores: la vida pública que se vuelve íntima, la vida privada que se vuelve pública.

Las celebraciones festivas de todo tipo fueron otro medio importante para establecer y reforzar relaciones de amistad entre los vecinos. De esta forma, las fiestas patrias, las celebraciones religiosas o los cumpleaños se convertían en excelentes pretextos para organizarse, convivir y compartir a través de la música, la comida, el baile, la bebida, el trabajo colaborativo y las creencias comunes. Esto, al parecer, ocurría más en unas cuadras que en otras. Ahora bien, al ser festivas, este tipo de prácticas generaron una percepción positiva de dichas relaciones entre los vecinos. 
Era cumpleaños de don Julio, por decir un ejemplo, pues sacaba don Julio desde temprano... su consola, porque tenía consola, era el rico de la calle (...). Bueno, sacaba su consola y tocaba sus canciones y ya sabíamos que en la noche iba a haber fiesta (...) desde la tarde, sacábamos todos los vecinos sillas y cerrábamos el paso de un lado y de otro lado de la cuadra, y toda la cuadra era fiesta. Alguien sacaba una mesa, otra persona llegaba con una olla grandota y le poníamos... bueno, le ponían, yo no [ríe], coca-cola, esteeeee... ron (...) ponían música bailable, se ponían a bailar, se ponían a cantar, y se ponía toda la bola así. Entonces los niños mientras andábamos jugando para un lado y para otro, y corríamos y brincábamos, y etc. (...) Eran convivencias muY bonitas. (Ernesto, entrevista 2018)

En general, el uso y apropiación de los espacios por parte de los vecinos de la colonia González Gallo permite dar cuenta de una gramática social particular -reflejada en una serie de códigos y patrones de conducta- que se fue construyendo a través de la interacción cotidiana. Sin embargo, fue la participación en el tipo de festividades mencionadas en la entrevista lo que muestra con mayor claridad la fuerte integración social que vivieron los primeros pobladores de la colonia, quienes lograron trascender las relaciones puramente vecinales para convertirlas en relaciones de amistad. Todo ello les permitió construir un fuerte apego tanto al grupo de vecinos como al territorio o, en otras palabras, un fuerte sentido de pertenencia socioterritorial.

\section{Conclusiones}

El espacio de representación, o espacio vivido, asociado con las experiencias que tienen los sujetos en el espacio, se encuentra estrechamente vinculado con las representaciones del espacio (o espacio concebido), objetivado en la morfología de las ciudades (Lefebvre, 1978, 2013). Si bien esta relación no es determinante ni unidireccional, sino dinámica y variable, las características morfológicas tanto de los espacios como de los colectivos sociales que los habitan influyen en las prácticas que realizan y en las representaciones que tienen los sujetos. Cuando esta relación permite reconocer y establecer un orden espacio-temporal y afianzar las relaciones sociales gracias a una serie de valores y principios compartidos, es posible hablar de la construcción de un sentido de pertenencia socioterritorial, como sucedió por lo menos en las primeras dos décadas de vida de la colonia.

Las calles peatonales, los espacios públicos centrales y los bienes y servicios cercanos contemplados como parte integral del proyecto desempeñaron un papel medular en las relaciones que establecieron los vecinos, ya que representaron espacios de encuentro y socialización, de creación y recreación de la vida comunitaria, donde los sujetos construyeron e interiorizaron, a partir de sus prácticas, un orden social determinado. Por otro lado, los distintos tamaños y precios de las casas permitieron la coexistencia e interacción de clases sociales diferentes en el espacio de la colonia. Esto generó un sentimiento de destino compartido y de preocupación por el otro, reflejado en acciones concretas como, por ejemplo, el cuidado de los menores de edad, las ayudas que se procuraban los vecinos en el transcurso de la 
vida cotidiana y la organización y participación en festividades a través de las cuales reforzaron sus vínculos vecinales y de amistad.

En cuanto al perfil de los residentes -más allá de lo cuestionable que pudieran resultar algunos de los criterios que se utilizaron para seleccionarlos, como aquellos que aluden a su probidad moral-, se garantizó una relativa homogeneidad en cuanto a sus valores, facilitando con ello la interacción e integración entre los sujetos. Asimismo, las familias llegaron a habitar la colonia con hijos pequeños, quienes, al poder jugar en las calles y en los espacios públicos centrales sin riesgo alguno, y ello por la ausencia tanto de vehículos como de personas ajenas a la colonia, contribuyeron al establecimiento de relaciones sociales entre los adultos encargados de su cuidado, particularmente las mujeres madres de familia. Por otro lado, el contexto de la época influyó también en los modos de vida que se pudieron generar en la colonia, ya que en ese tiempo la inseguridad que existía era mínima, dando pie a que las familias vivieran de forma tranquila en un espacio propio.

Si bien en la actualidad el contexto es muy diferente al de hace setenta años, algunas lecciones se pueden aprender de este proyecto para la reconfiguración del espacio urbano. Por un lado, la importancia de contar con espacios públicos seguros -ya sea por la ausencia de tráfico vehicular o por la vigilancia que sobre ellos puedan tener los vecinos-, así como cercanos a las viviendas; la existencia de distintos tipos de bienes y servicios en la colonia -comercios, escuelas, hospital-, ya que posibilitan que los sujetos entren en contacto de manera cotidiana y satisfagan sus principales necesidades; la mezcla entre grupos socioeconómicos diferentes, que permite que los sujetos compartan un destino común; la existencia de vialidades y rutas de transporte público, que facilita a los residentes acceder a otros puntos de la ciudad y a lo que en ellos se ofrece. Si bien este último punto no se aborda en este trabajo, no por ello es menos importante.

Ante la dispersión, segregación e inseguridad que padecen actualmente muchos núcleos urbanos, como el de Guadalajara, pensar en proyectos urbano-arquitectónicos con estos elementos pudiera ayudar a reconstruir los lazos vecinales y a generar un sentido de comunidad de base territorial; o, en otras palabras, un sentido de pertenencia socioterritorial. Por supuesto que no hay fórmulas para planear el espacio urbano ni controlar lo que en él sucede. La vida social es muy compleja y siempre tiene un cierto grado de indeterminación e incertidumbre. Pensar lo contrario sería ingenuo. Sin embargo, es cierto que hay elementos -tanto físicos como sociales- que pueden facilitar las relaciones entre vecinos, como algunos de los expuestos en este trabajo, sin pasar por alto que la construcción de lazos de confianza requiere tiempo, cercanía, disposición, constancia y reciprocidad, que resultan cada vez más difíciles de construir. No contribuyen a ello las características de la sociedad contemporánea, que induce a los sujetos a una mayor movilidad residencial así como a una precarización de las relaciones sociales, como resultado de lo limitado del tiempo libre de que disponen.

Como corolario, solo resta decir que la pertenencia socioterritorial es siempre resultado de un proceso de habitar, esto es, de un proceso de vivir y representar el espacio, de socializar con los otros, de interiorizar y recrear un orden social, de ser y sentirse parte de él. 


\section{Referencias bibliográficas}

Ángel de León, E. (2001). La colonia de la Habitación Popular no. 1, o, Colonia J. Jesús González Gallo. Amate.

Arias, P. (1992). La vida económica tapatía en el siglo xx. En L. Rendón (Coord.), Capitulos de historia de la ciudad de Guadalajara. Tomo II (pp. 59-85). Ediciones Guadalajara 450 ańos. Ayuntamiento de Guadalajara 1989-1992.

Berger, P. \& Luckmann, T. (2005). La construcción social de la realidad. Amorrortu.

Bourdieu, P. (2007). Razones prácticas. Sobre la teoría de la acción. Anagrama.

Bourdieu, P. (2009). El sentido práctico. Siglo Veintiuno.

Bourdieu, P. (2011). Capital cultural, escuela y espacio social. Siglo Veintiuno.

Castells, M. (1976). La cuestión urbana. Siglo Veintiuno.

Convocatoria. (1948, enero 21). El Informador, p. 2. http://hemeroteca.informador.com.mx/

Duhau, E. \& Giglia, A. (2008). Las reglas del desorden: habitar la metrópoli. Universidad Autónoma Metropolitana - Azcapotzalco / Siglo Veintiuno.

Duhau, E. \& Giglia, A. (2016). Metrópoli, espacio público y consumo. Fondo de Cultura Económica.

El Patronato de la Habitación Popular. (1951, marzo 3). El Informador, p. 7. http://hemeroteca. informador.com.mx/

El Proyecto de la Habitación Popular, en la Legislatura. (1947, septiembre 9). El Informador, pp. 1, 2a. http://hemeroteca.informador.com.mx/

El Segundo Sorteo de Casas Populares se Efectuó Ayer. (1951, enero 1). El Informador, pp. 1, 6a. http://hemeroteca.informador.com.mx/

Esquivel-Hernández, M. (2005). Vida cotidiana e identidad. En S. Tamayo \& K. Wilder (Coords.), Identidades urbanas (pp. 57-89). Universidad Autónoma Metropolitana (México).

Giglia, A. (2012). El habitar y la cultura. Perspectivas teóricas y de investigación. Anthropos I Universidad Autónoma Metropolitana (México).

Giménez, G. (2007). Estudios sobre la cultura y las identidades sociales. Consejo Nacional para la Cultura y las Artes / Instituto Tecnológico y de Estudios Superiores de Occidente (ITESO) - Universidad Jesuita de Guadalajara.

González-Varas, I. (2014). Las ruinas de la memoria. Ideas y conceptos para una (im)posible teoría del patrimonio cultural. Siglo Veintiuno / El Colegio de Sinaloa.

Haesbaert, R. (2011). El mito de la desterritorialización. Del "fin de los territorios" a la multiterritorialidad. Siglo Veintiuno.

Halbwachs, M. (2004). La memoria colectiva. Universidad de Zaragoza.

Heidegger, M. (1994). vi. Construir, pensar, habitar. Conferencias y artículos (pp. 127-162). Ediciones del Serbal.

Heller, Á. (1977). Sociología de la vida cotidiana. Península.

Jacobs, J. (2013). Muerte y vida de las grandes ciudades. Capitán Swing.

Juan, S. (2008). Un enfoque socio-antropológico sobre la vida cotidiana: automatismos, rutinas, elecciones. Espacio abierto Cuaderno Venezolano de Sociología, 17(3), 431-454. https://www.redalyc.org/articulo.oa?id=12217304

Lefebvre, H. (1978). El derecho a la ciudad. Península.

Lefebvre, H. (2013). La producción del espacio. Capitán Swing. 
Lindón, A. (2000). Del campo de la vida cotidiana y su espacio-temporalidad (una presentación). En A. Lindón (Coord.), La vida cotidiana y su espacio-temporalidad (pp. 7-18). El Colegio Mexiquense / Anthropos.

Lindón, A. (2014). El habitar, las redes topológicas del urbanita y la figura del transeúnte. En D. Sánchez González \& L. Á. Domínguez Moreno (Coords.), Identidad y espacio público. Ampliando ámbitos y prácticas (pp. 55-76). Gedisa.

López-Moreno, E. (1996). La vivienda social: una historia. Universidad de Guadalajara / Universidad Católica de Lovaina / оRSTOM / Red Nacional de Investigación Urbana.

Mayol, P. (2006). Capítulo I. El barrio. En M. de Certeau, L. Giard \& P. Mayol, La invención de lo cotidiano 2. Habitar, cocinar (pp. 5-32). Universidad Iberoamericana / Instituto Tecnológico y de Estudios Superiores de Occidente (ITESO) - Universidad Jesuita de Guadalajara.

Nates, B. (2011). Presentación. En B. Nates \& F. C. Londoño (Coords.), Memoria, espacio y sociedad (pp. 7-10). Anthropos / Instituto de Investigaciones en Ciencias Sociales y Humanas / Universidad de Caldas.

Núñez-Miranda, B. (1999). Guadalajara, una visión del siglo xx. El Colegio de Jalisco.

Ortiz-Guitart, A. (2006). Uso de los espacios públicos y construcción del sentido de pertenencia de sus habitantes en Barcelona. En A. Lindón, M. Á. Aguilar \& D. Hiernaux (Coords.), Lugares e imaginarios en las metrópolis (pp. 67-83). Anthropos / Universidad Autónoma Metropolitana - Iztapalapa (UAM-I).

Raffestin, C. (2013). Por una geografía del poder. El Colegio de Michoacán / Fideicomiso Felipe Teixidor y Monserrat Alfau de Teixidor.

Reguillo, R. (2000). La clandestina centralidad de la vida cotidiana. En A. Lindón (Coord.), La vida cotidiana y su espacio temporalidad (pp. 77-93). Anthropos.

Rueda-Velázquez, C. (2019). La habitación popular moderna en Guadalajara. Permanencias y transformaciones. Academia XXI,, 10(20), 72-89. http://doi.org/10.22201/ fa.2007252Xp.2019.20.72314

Siqueiros, L. F. (2012). Capítulo I. El territorio, el medio ambiente y las condiciones urbanas. En G. Rodríguez Gómez (Coord.), La realidad socialy las violencias. Zona Metropolitana de Guadalajara (pp. 33-69). Comisión Nacional para Prevenir y Erradicar la Violencia contra las Mujeres (CONAvim) / INCIDE Social / Centro de Investigaciones y Estudios Superiores en Antropología Social (CIESAS) / Instituto Tecnológico y de Estudios Superiores de Occidente (ITESO).

Vázquez, D. (1992). La urbanización de Guadalajara. En L. Rendón (Coord.), Capitulos de historia de la ciudad de Guadalajara. Tomo I (pp. 37-70). Ediciones Guadalajara 450 años. Ayuntamiento de Guadalajara 1989-1992. 